\title{
Infection control Knowledge, Practices, and Perceived barriers towards COVID-19 among physicians in university hospitals, Cairo, Egypt.
}

Rasha Saad Hussein ( $\nabla$ rasha_saad@med.asu.edu.eg )

Faculty of Medicine, Ain Shams University https://orcid.org/0000-0003-4139-2971

Shimaa A. Abdel-Salam

Faculty of Medicine, Ain Shams University

Asmaa F. Gebrel Mohamed

Faculty of Medicine, MUST University

\section{Research Article}

Keywords: COVID-19, Knowledge, infection control practices, Barriers

Posted Date: November 20th, 2020

DOl: https://doi.org/10.21203/rs.3.rs-110956/v1

License: (c) (i) This work is licensed under a Creative Commons Attribution 4.0 International License.

Read Full License 


\section{Abstract}

Background: WHO declared COVID-19 a global pandemic on 11th March 2020. Due to the lack of adequate treatment and approved vaccines, proper infection control practices are the only effective tools for prevention and control of COVID-19 infection among the health care facilities.

Objectives: This study aimed to assess the infection control knowledge, practices, and perceived barriers towards COVID-19 among physicians working at Ain Shams University hospitals.

Methods: Cross-sectional was carried out among a sample of physicians working at Ain Shams university hospitals, Cairo, Egypt, by using an online questionnaire. The design of the questionnaire was based mainly on the WHO guidance for infection prevention and control during health care when novel coronavirus infection is suspected and CDC guidance for COVID-19.

Results: A total of 318 physicians with different job titles and specialties participated in this study, results showed average infection control knowledge (the mean correct answer rate was $57.1 \%+15.9 \%$ ) and practices (infection control practices score was $78.76 \% \pm 12.17 \%$ ) among our studied group. Patients overload and improper design of the working places were perceived as barriers to infection control practices by the majority $(90 \%)$ of our participants.

Conclusion: Our study results showed average infection control knowledge and practices towards COVID19. There are defects in certain aspects related to infection control knowledge and practices that needed more practical training and properly designed working places to improve it.

\section{Background}

On 31st December 2019, it was announced the presence of viral pneumonia of unknown cause in Wuhan city, China. The pathogen causing this pneumonia has been defined as severe acute respiratory syndrome coronavirus-2 (SARS-CoV-2) [1].

SARS-COV-2 is an enveloped single-stranded RNA virus, previously known as 2019-nCov, and causing a disease called Coronavirus disease 2019 (COVID-19) [2-3].WHO declared coronavirus disease 2019 (COVID-19) as a global pandemic on 11th March 2020 [4].

SARS-COV-2 is a highly transmissible viral infection. It got discovered more than twenty million people were infected worldwide. It is transmitted from person-to-person by close contact via the respiratory droplets during coughing and sneezing or through touching contaminated surfaces by the virus [5-6].

Due to the lack of adequate treatment and approved vaccines. The WHO recommends for the prevention of COVID-19 spread to apply primary preventive measures that include Proper hand washing, physical distancing, respiratory hygiene, cough etiquette, and wearing face masks in crowded areas that 
will serve as the first line of defense in public and also applying effective infection control measures within the different health care settings [7-8].

Physicians are at the front-line of COVID-19 fighting during this pandemic. They are exposed to infection due to frequent contact with and exposure to confirmed and suspected cases. They are also exposed to psychological stress, fatigue due to long working hours, and physical violence [9-10].

The transmission of COVID 19 among physicians is enhanced by multiple factors as patients overcrowding, lack of isolation rooms within the health care facilities, soiled environment by patient secretions, and absence of knowledge or insufficient awareness of infection control practices among them [11]. A prospective cohort study has been conducted in the UK and the USA to compare the risk of COVID-19 infection among front-line Health care workers (HCWs) with the general community. The result revealed that front-line HCW had a twelvefold increase in the risk of COVID- 19 infection [12]

Understanding physicians' knowledge, attitudes, and possible perception of risk of infection directly influence practices and lead to proper diagnosis and decrease the spread of disease. So, this study has been conducted to assess the infection control knowledge, practice, and perceived barriers toward COVID19 among physicians at Ain Shams University, Egypt.

\section{Methods}

Study design, setting, and population: This Cross-sectional survey has been carried out among physicians working at Ain Shams university hospitals, Cairo, Egypt, using an online questionnaire in English language form from 1 June to 30 July 2020. During this period, most of the Physicians worked at either the emergency units or at the COVID-19 isolation hospital, so it was not feasible to contact them, we have been designing an online questionnaire to allow proper reaching to our target population.

Ain Shams university hospital is one of the largest university hospitals in Egypt, it includes 7 hospitals (surgery hospital, internal medicine hospital, pediatrics hospital, obstetrics, and gynecology hospital, emergency hospital, and geriatrics hospital), and multiple specific units and centers as clinical toxicology center, psychiatric center, bone marrow transplant unit, digestive endoscopy unit and clinical research unit. It involves more than 3000 inpatient beds, in addition to ICUs at the different hospitals.

Our study population represents physicians with different specialties and positions, who working at Ain Shams university hospitals. The sample size has been calculated using the PASS11 program based on reviewing results of previous relevant studies which have shown that the mean correct answer rate of knowledge related to COVID-19 was (80.4\%) [13], and good infection control practices were (94.3\%) [7], with a margin of error $=0.05$ and at $95 \%$ confidence level. The required sample size was 250 physicians, but at the end of the specified time period, the collected sample was 318 physicians.

Data collection tool: Data has been collected using an anonymous online questionnaire. The design of the questionnaire mainly was based on the WHO guidance for infection prevention and control during 
health care when novel coronavirus infection is suspected [8], and CDC guidance for COVID-19[14]. The validity of the items has been verified by three experts, including microbiologists, infection control specialties and epidemiologists. A pilot study has been conducted on 10 physicians before the gathering of data. The data of this study has been excluded from the final analysis. The questionnaire has been created on Google Forms. The URL link has been shared with all physicians on the WhatsApp group so that they can participate in the questionnaire.

The questionnaire was composed of four sections:

1. Demographic data (e.g. age, gender, specialty).

2. Level of COVID-19 Related infection control Knowledge: Knowledge has been assessed using 12 questions covering mode of transmission and general infection control practices. Each question has been answered as follows: yes, no, or I don't know. The correct answer was assigned 1 point and an incorrect answer or 'I don't know' were assigned 0 points. The total score ranged from 0-12 and has been converted into a percentile.

3. Infection control practices: This section consisted of nine items covering the infection control practices related to applying the standard precautions and other WHO recommended empirical precautions during contact suspicious or confirmed COVID-19 cases. The choices were provided as 'Rare, sometimes' or Always, and answers have been coded as rare $=1$, sometimes $=2$, and always $=3$. The total score ranged from 0 to 27 and has been converted to a percentile.

4. Infection control perceived barriers: Based on reviewing results from a previous study [7], six items have been selected to assess the perception of physicians regarding infection control barriers. Responses have been coded as yes, or no for each barrier.

Data management and analysis: Data have been revised, coded and analyzed using SPSS package version number 25. Quantitative data has been described as mean, standard deviation (SD), and range values. Qualitative data has been described as numbers and percentages.

To study the association between the physicians' socio-demographic characteristic and their infection control knowledge and practice scores, independent t-test, and ANOVA test have been used. P-value $\leq$ 0.05 has been considered significant.

\section{Results}

A total of 318 physicians with different job titles and specialties have participated in our study (mean age $30.18+6.07$ years; $[60.7 \%]$ females), and about half of them (52.5\%) reported previous attendance of infection control course. Table1

Table 1. Socio-demographic characteristics of the study group $(\mathrm{N}=318)$ 


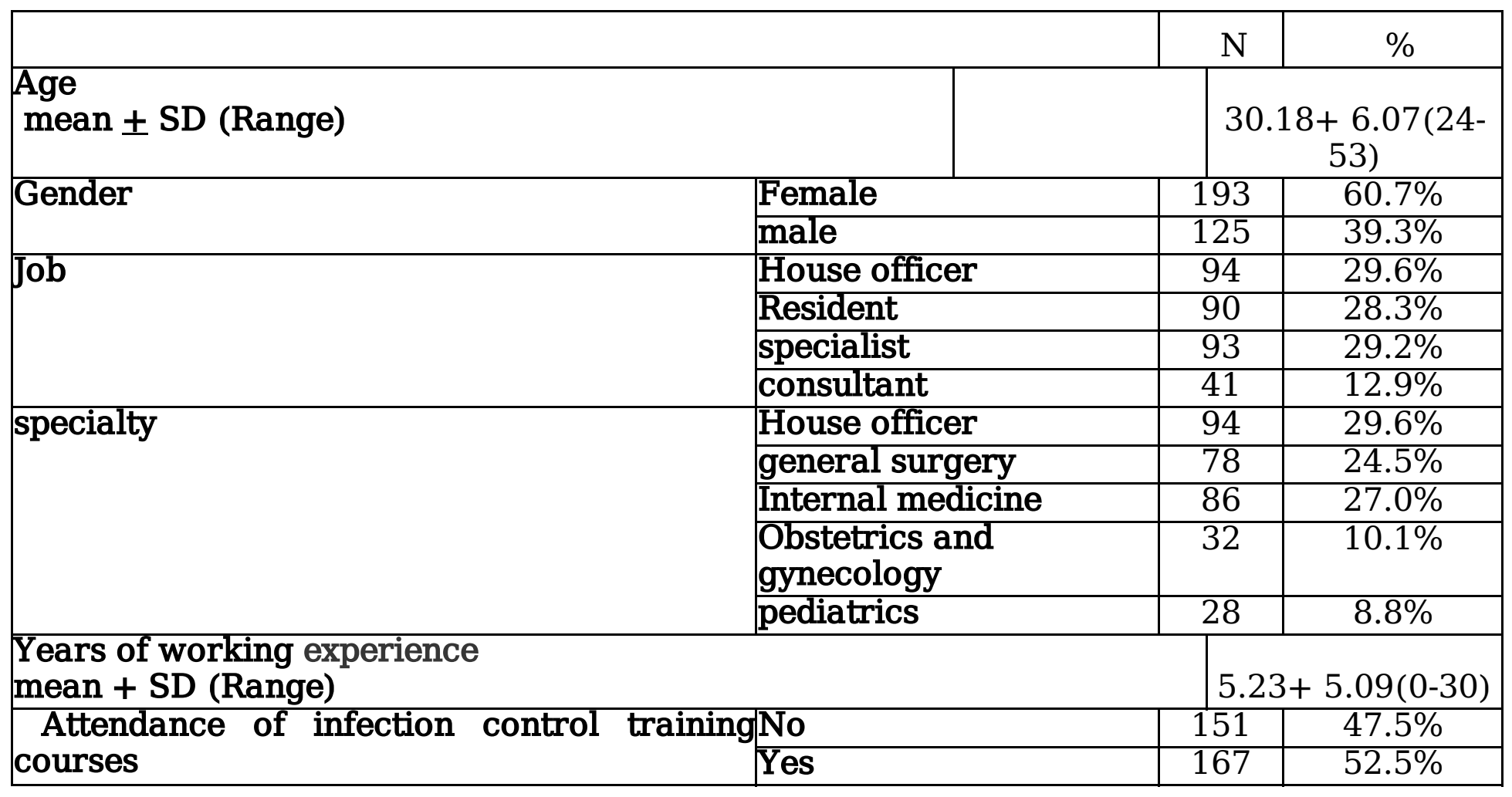

Assessment of Covid-19 related knowledge has revealed that the mean correct answer rate was ( $57.1+$ 15.9), the highest correct answer was related to the item" Washing hands with soap or use of an alcoholbased antiseptic decrease the risk of the infection" as $99.7 \%$ of the participants answered it correctly. While the least correct answer was related to the item "All types of face masks have the same protection level against the infection" as only $3.6 \%$ of the participants answered it correctly. Table2 Table 2. Physicians' knowledge about COVID 19 dynamics and prevention ( $N=318)$ 
The knowledge items

1. COVID-19 is spread from person to person through infectious Droplets (Yes)

2. Gloves can provide complete protection against transmission of COVID19(No)

3. Washing hands with soap or use of an alcohol-based antiseptic decreases the risk of the infection (Yes)

4. Maintain 1-1.5 meters distance between you and others decrease the risk of infection transmission (Yes)

5. Face mask decrease the risk of transmission of COVID from a case to others (Yes)

6. COVID cases can't transmit the infections when fever is not present (No)

7. Contacts to COVID cases must be isolated in proper place for 14 days (Yes)

8. Isolation of the cases must be done at a negative pressure room (NO)

9. All types of face masks have the same protection level against the infection (NO)

10. The same personal protective requirements set (PPE) used for all medical producers done for COVID cases (NO)

11. Do you know the correct sequence of donning PPE? (Yes)

12. Do you know the correct sequence of Doffing PPE? (Yes)

Total Knowledge score: mean \pm SD (Range)

Total knowledge score \%: mean + SD (Range)

$66(20.8 \%)^{*}$

\section{(*) Items with lowest correct answers percentages}

Regarding the self-reported infection control practices assessment, the mean practice score was 78.76 +12.17 , most of our participants reported that they have been safely disposing of the used PPE. While only (20.8\%) of them reported that they were always making seal test for N95 mask before use. Table 3

Table 3: Physicians' infection control practices $(\mathrm{N}=318)$ 


\begin{tabular}{|c|c|c|}
\hline of infection control practices & & $\mathrm{N}(\%)$ \\
\hline ly hand hygiene in a proper way and according to WHO 5 & rare & $5(1.6 \%)$ \\
\hline lents & Sometimes & $127(39.9 \%)$ \\
\hline & Always & $186(58.5 \%)$ \\
\hline ig PPE in a proper way & rare & $26(8.2 \%)$ \\
\hline & Sometimes & $157(49.4 \%)$ \\
\hline & Always & $135(42.5 \%)$ \\
\hline g N95 mask During all patient management procedures & rare & $97(30.5 \%)$ \\
\hline & Sometimes & $146(45.9 \%)$ \\
\hline & Always & $75(23.6 \%) *$ \\
\hline ing seal test for N95 mask before use & rare & $154(48.4 \%)$ \\
\hline & Sometimes & $98(30.8 \%)$ \\
\hline & Always & $66(20.8 \%)^{*}$ \\
\hline hing hand between steps of doffing PPE & rare & \begin{tabular}{|l|l|}
$79(24.8 \%)$ \\
\end{tabular} \\
\hline & Sometimes & $106(33.3 \%)$ \\
\hline & Always & $133(41.8 \%)$ \\
\hline nging the torn gloves immediately after proper hand washing & rare & \begin{tabular}{|l|l|}
$16(5.0 \%)$ \\
\end{tabular} \\
\hline & Sometimes & $66(20.8 \%)$ \\
\hline & Always & $236(74.2 \%)$ \\
\hline nging Medical/surgical mask if it get wet during work & rare & $32(10.1 \%)$ \\
\hline ediate & Sometimes & $90(28.3 \%)$ \\
\hline & Always & $196(61.6 \%)$ \\
\hline g single use gloves for one patient & rare & $31(9.7 \%)$ \\
\hline & Sometimes & $88(27.7 \%)$ \\
\hline & Always & $199(62.6 \%)$ \\
\hline sable of used PPF in infectious waste & rare & $12(3.8 \%)$ \\
\hline & Sometimes & $42(13.2 \%)$ \\
\hline & Always & $264(83.0 \%)$ \\
\hline tion control practices score: mea & $21.26 \pm 3$ & $29(12-27)$ \\
\hline ;tion control practices score \%: m & $78.76 \pm 1$ & $\begin{array}{l}2.17(44.4- \\
00)\end{array}$ \\
\hline
\end{tabular}

(*) Items with lowest self-reporting infection control practices

Table 4, Shows the association between socio-demographic characteristics and the level of COVID-19 related knowledge, the mean knowledge score was significantly higher in the old age group(>30 years), males, consultants, pediatric specialty, and among physicians who attended infection control courses. Regarding the safe infection control practices, participants who attended infection control courses have a significantly higher safe practice than others.

Table 4: Relation between socio-demographic characteristics and their infection control knowledge and practices scores regarding COVID-19. 


\begin{tabular}{|c|c|c|c|c|c|c|c|}
\hline & \multicolumn{3}{|c|}{$\begin{array}{l}\text { Mean Knowledge } \\
\text { score \% }\end{array}$} & \multicolumn{3}{|c|}{$\begin{array}{c}\text { Mean infection } \\
\text { control practices \% }\end{array}$} \\
\hline & & Mean & SD & P value & Mean & SD & P value \\
\hline \multirow[t]{2}{*}{ Age } & $<=30$ & 58.65 & 15.3 & & 78.59 & 12.30 & \\
\hline & $>30$ & 54.24 & 16.6 & $0.018 * ¥$ & 79.07 & 11.98 & 0.73 \\
\hline \multirow[t]{2}{*}{ Gender } & Female & 54.7 & 15.2 & & 78.41 & 11.62 & \\
\hline & male & 60.7 & 16.2 & $0.001 * ¥$ & 79.29 & 13.00 & 0.53 \\
\hline \multirow[t]{4}{*}{ Job title } & House officer & 52.85 & 15.77 & & 80.06 & 12.79 & \\
\hline & Resident & 56.48 & 15.59 & & 76.21 & 12.30 & \\
\hline & specialist & 55.73 & 16.07 & & 79.77 & 12.78 & \\
\hline & consultant & 60.90 & 15.60 & $0.027 * \square$ & 79.04 & 7.80 & 0.12 \\
\hline \multirow[t]{5}{*}{ specialty } & House officer & 52.85 & 15.77 & & 80.06 & 12.79 & \\
\hline & general surgery & 54.70 & 15.05 & & 77.49 & 11.99 & \\
\hline & Internal medicine & 53.39 & 15.15 & & 77.86 & 12.22 & \\
\hline & $\begin{array}{l}\text { Obstetrics and } \\
\text { gynecology }\end{array}$ & 58.33 & 16.93 & & 79.86 & 12.76 & \\
\hline & pediatrics & 61.01 & 17.58 & $30.008 * \square$ & 79.37 & 9.69 & 0.61 \\
\hline \multirow[t]{3}{*}{ Years of working experience } & 0 to5 & 59.19 & 15.63 & & 79.81 & 11.78 & \\
\hline & $>5-10$ & 54.67 & 15.89 & & 78.11 & 12.32 & \\
\hline & $>10$ & 54.44 & 16.09 & $0.034 * \square$ & 76.91 & 12.81 & 0.14 \\
\hline \multirow{2}{*}{$\begin{array}{l}\text { Attending infection control } \\
\text { training courses }\end{array}$} & No & 53.5 & 15.2 & & 77.04 & 10.99 & \\
\hline & Yes & 60.3 & 15.8 & $<0.001^{* \text { * }}$ & 80.31 & 12.99 & $0.01 *$ \\
\hline
\end{tabular}

\section{- Significant () ANOVA (¥)independent $t$ test}

Patients' overload and improper design of the working places have been mentioned as perceived as barriers to infection control by the majority (90\%) of our participants. Table 5 Table 5: Infection control perceived barriers. 


\begin{tabular}{|l|l|}
\hline Perceived barriers & $\%$ \\
\hline - Less commitment of health care workers to the infection control policies & $77.80 \%$ \\
\hline - Insufficient training on infection control measures & $87.20 \%$ \\
\hline - Overcrowding of the emergency room & $89 \%$ \\
\hline - limitation of materials needed to apply infection control practices & $89.50 \%$ \\
\hline - Patients overload & $90 \%$ \\
\hline - Narrow and improper design of the working places & $90 \%$ \\
\hline
\end{tabular}

\section{Discussion}

Our study results have revealed that physicians have an average level of COVID-19 related knowledge, the mean correct answer rate was $57.1 \%+15.9 \%$. This is consistent with the results of a study conducted in the United Arab Emirates And another study conducted in Iran as the level of knowledge was $61 \%$ and $56.5 \%[15,16]$ But, lower than that reported in other studies conducted in Egypt, China, Vietnam and Uganda as the knowledge correct answer rate were $80.4 \%, 90 \%, 88.4 \%$, and $82.4 \%$ respectively $[17,18,19,20]$. These dissimilarities could be due to differences in the characteristics of the surveyed populations and the scientific level of the items used in evaluating the degree of the infection control knowledge among different studies.

In the current study, the most prevalent correct answers were related to the importance of hand washing with soap or the use of an alcohol-based antiseptic in decreasing the risk of the infection (99.7\%), and the importance of maintenance of social distance (97.5\%). These results are similar to that have been mentioned in two studies conducted among Saudi HCWs, and Indian undergraduate students were participants reported the importance of hand hygiene before touching the patients in a percentage of $94.1 \%$ and $85.4 \%$ respectively $[21,22]$.while the importance of social distancing was in line with a study conducted in El Fayoum governorate, Egypt and another study conducted in Iran as $97 \%$ of the participants reported that coronavirus spread via close contact $[13,23]$

Knowledge level about COVID-19 has been significantly associated with younger age groups (less than 30 years old). Several studies results have found that the younger age group has a higher level of knowledge $[17,18,24]$, contrary to other studies that have shown that a higher level of knowledge has associated with the older age group $>30$ years old $[25,26]$. While other studies have reported that there has no association between knowledge and age [27, 28].

In the present study, a statistically significant relationship between physicians' knowledge and their years of experience was detected. This result is dissimilar to that have been mentioned in a study conducted in Pakistan as there was no association between years of experience and the knowledge level [29], on the 
other hand, other studies have shown that the mean knowledge score was significantly higher among those who had more than ten years of experience $[25,30]$.

Regarding infection control practices we found that the mean infection control practices score was (78.76 \pm 12.17$)$, this is in accordance with a study done in Saudi Arabia as $87.9 \%$ of health care workers reported good infection control practice [25].

In our study, the most prevalent correct practice was related to hand washing as only $5 \%$ of our participants rarely apply proper hand washing, while $58.5 \%$ of them always apply it properly. This is higher than that has been found in a study conducted in Brazil as the hand washing adherence rate was $46.25 \%$ in critical care unit [31]

About $58.5 .5 \%$ of the studied group always wears PPE, while only $8.2 \%$ rarely wears it properly and $23 \%$ always Uses N95 mask during all patient management procedures, this is in line with a study conducted in Saudi Arabia which has reported that $71 \%$ of health workers wear the mask during work [32]. Another study that has been carried out in Pakistan has shown that the correct usage of masks was good in $35.2 \%$, moderate in $45.4 \%$, and poor in $19.3 \%$ of the studied group [33].In contrast, a study has been carried out in Vietnam has reported that there is a limited number of correct responses regarding items related to the use of personal protective equipment [34].

Our results have revealed that the previous attendance of infection control training courses was the only significant factor affecting physicians' infection control practices. This result reflects the importance of practical training and learning by doing as essential and mandatory requirements for applying proper infection control practices.

Patients' overcrowding and limited infection control material have been reported as perceived barriers by the majority of our study participants, this is consistent with the results of other relevant studies that mentioned these factors as barriers to infection control practices [17, 29, and 35].

\section{Limitations}

Our study has been conducted among a sample of physicians who have accepted to fulfill the online questionnaire. Lack of presentation of all physicians has interfered with the generalization of our results.

\section{Conclusion}

The overall Knowledge and practice of physicians regarding the infection control were found to be on average compared to other studies. Patients overload, improper design of the working places, limitations of materials needed to apply infection control measures and insufficient infection control training measures were perceived as barriers to infection control by most of our participants. Continues infection control training, providing adequate supplies of PPE and proper designing of working places are essential requirements for infection control practices within the health care facilities. 


\section{Abbreviations}

CDC: Centers for Disease Control and prevention

COVID-19: Coronavirus Disease 2019

HCWs: Health Care Workers

ICUs: Intensive Care Units

PPE: Personal Protective Equipment

SARS: Sever Acute Respiratory Syndrome

WHO: World Health Organization

\section{Declarations}

- Ethics approval and consent to participate: The research ethics committee (REC) in the Faculty of Medicine, Ain Shams University approved this study (Approval number: FMASU R 50/2020). Filling the questionnaire by physicians is considered an approval to participate in the study. Confidentiality of data has been maintained through the anonymity of the questionnaire.

- Consent for publication: Not applicable

- Availability of data and material: The datasets generated and analyzed during the current study are available from the corresponding author on request.

- Competing interests: The authors state that they have no competing interests.

- Funding There has been no significant financial support for this work that could have influenced its outcome.

\section{- Author Contributions:}

RS conceptualized the study idea, designed the online form, analyzed the data, and was a major contributor in writing the manuscript. SA conceptualized the study idea and participated in writing the manuscript. AF participated in writing and editing the draft of the manuscript. All authors participated in data collection. All authors have read and approved the manuscript

- Acknowledgements Authors would like to express their great appreciation to participants who generously shared their time and agreed to participate in this study

\section{References}

1. Huang, C., Wang, Y., Li, X., Ren, L., Zhao, J., Hu, Y., et al. Clinical features of patients infected with 2019 novel coronavirus in Wuhan, China. The lancet. (2020);395(10223), pp.497-506. DOI: 
10.1016/S0140-6736(20)30183-5.

2. World Health Organization. Coronavirus disease 2019 (COVID-19) Situation Report-51. Geneva: WHO. (2020). Retrieved May13, 2020 from www.who.int/emergencie s/diseases/novel -coronavirus2019/situation-reports. Last accessed Sept.2020

3. Guan, W., Ni, Z., Hu, Y., Liang, W.H., Ou, C.Q., He, J.X., et al. Clinical characteristics of coronavirus disease 2019 in China. New England Journal of Medicine. (2020);382(18), pp.1708-1720. https ://doi.org/10.1056/nejmo a2002 032.

4. World Health Organization. WHO Director-General's opening remarks at the media briefing onCOVID19e11 March2020.Geneva: WHO;2020.Available at: https://www.who.int/dg/speeches/detail/whodirector-general-s-opening-remarks-at-the-mediabriefing-on-covid-19-11-march-2020. Last accessed Sept.2020

5. Song, P. and Karako, T. COVID-19: Real-time dissemination of scientific information to fight a public health emergency of international concern. Bioscience trends. 2020;14(1):1-2. PMID: 32092748. DOI: 10.5582/bst.2020.01056.

6. Li, Q., Guan, X., Wu, P., Wang, X., Zhou, L., Tong, Y. et al. Early transmission dynamics in Wuhan, China, of novel coronavirus-infected pneumonia. New England Journal of Medicine. (2020) ; 382, 1199-1207. https ://doi. org/10.1056/NEJMo a2001 316. DOI: 10.1056/NEJMoa2001316

7. Salman, M., Mustafa, Z.U., Asif, N., Zaidi, H.A., Hussain, K., Shehzadi, N. et al. Knowledge, attitude and preventive practices related to COVID-19: a cross-sectional study in two Pakistani university populations. Drugs \& Therapy Perspectives. 2020; May 9:1. DOI: https://doi.org/10.1007/s40267020-00737-7

8. World Health Organization. Infection prevention and control during health care when novel coronavirus (nCoV) infection is suspected, World Health Organization: Geneva (2020). Retrieved May 10, 2020 from https ://www.who.int. Last accessed Sept.2020.

9. World Health Organization. Coronavirus Disease (COVID-19) Outbreak: Rights, roles and responsibilities of health workers, including key considerations for occupational safety and health. (2020). Retrieved May 13, 2020 from www.who.int/publi cations-detail/coronavirus-disease-(covid19)-outbreak. Last accessed Sept.2020

10. Gan, W. H., Lim, J. W., \& Koh, D. Preventing intra-hospital infection and transmission of COVID-19 in healthcare workers. Safety and Health at Work, (2020); 11, 241. doi: 10.1016/j.shaw.2020.03.001

11. Wu, Z., \& McGoogan, J. M. Characteristics of and important lessons from the coronavirus disease 2019 (COVID-19) outbreak in China: Summary of a report of 72314 cases from the Chinese centre for disease control and prevention (2020). https ://doi.org/10.1001/jama.2020.2648.

12. Nguyen, L. H., Drew, D. A., Graham, M. S., Joshi, A. D., Guo, C. G., Ma, W.,et al. Risk of COVID-19 among front-line health-care workers and the general community: a prospective cohort study. The Lancet Public Health, (2020). 5(9), e475-e483. https://doi.org/10.1016/S2468-2667(20)30164-X

13. Abdel Wahed, W.Y., Hefzy, E.M., Ahmed, M.I.,Hamed M.I. Assessment of Knowledge, Attitudes, and Perception of Health Care Workers Regarding COVID-19, A Cross-Sectional Study from Egypt. J 
Community Health (2020). https://doi.org/10.1007/s10900-020-00882-0

14. CDC guidance document for coronavirus disease available at https://www.cdc.gov/coronavirus/2019-ncov/communication/guidance-list.html? Sort=Date\%3A\%3Adesc . Last accessed Sept.2020

15. Bhagavathula AS, Aldhaleei WA, Rahmani J, Mahabadi MA, Bandari DK. Knowledge and Perceptions of COVID-19 among Health Care Workers: Cross-Sectional Study. JMIR Public Health Surveill. 2020 Apr 30;6(2):e19160. doi: 10.2196/19160. PMID: 32320381; PMCID: PMC7193987.

16. Nemati, Marzieh \& Ebrahimi, Bahareh. Assessment of Iranian Nurses' Knowledge and Anxiety toward COVID-19 During the Current Outbreak in Iran. Archives of Clinical Infectious Diseases. In Press.2020. 10.5812/archcid.102848. doi: 10.5812/archcid. 102848

17. Abdelhafiz, A.S., Mohammed, Z., Ibrahim, M.E., Ziady,H.H., Alorabi,M.A.,Sultan,E.A.. Knowledge, Perceptions, and Attitude of Egyptians Towards the Novel Coronavirus Disease (COVID-19). J Community Health 45, 881-890 (2020). https:// doi.org/10.1007/s10900-020-00827-7

18. Zhang M, Zhou M, Tang F, Wang Y, Nie H, Zhang L, You G. Knowledge, attitude, and practice regarding COVID-19 among healthcare workers in Henan, China. J Hosp Infect. 2020 Jun;105(2):183187. doi: 10.1016/j.jhin.2020.04.012. Epub 2020 Apr 9. PMID: $32278701 ;$ PMCID: PMC7194961.

19. Huynh G, Nguyen TN, Tran VK, Vo KN, Vo VT, Pham LA. Knowledge and attitude toward COVID-19 among healthcare workers at District 2 Hospital, Ho Chi Minh City. Asian Pac J Trop Med [serial online] 2020 [cited 2020 Oct 7]; 13:260-5. Available from: https://www.apjtm.org/text.asp? 2020/13/6/260/280396

20. Olum R, Kajjimu J, Kanyike AM, Chekwech G, Wekha G, Nassozi DR, Kemigisa J, Mulyamboga P, Muhoozi OK, Nsenga L, Lyavala M, Asiimwe A, Bongomin F. Perspective of Medical Students on the COVID-19 Pandemic: Survey of Nine Medical Schools in Uganda.JMIR Public Health Surveill 2020;6(2):e19847. DOI: 10.2196/19847.

21. Al Mutairi SM, Alotaibi A, Kofi M, Alsuraimi A, Bawazir A.To What Extent the Hand Hygiene among Health Care Workers Become the Core of Best Practice in the COVID-19 Era?. Int Arch Nurs Health Care.2020; 6:144. doi.org/10.23937/2469-5823/1510144

22. Brahmbhatt KR, Lodhiya KK. Hand hygiene knowledge among undergraduate medical students in Junagadh, Gujarat, India. International Journal of Community Medicine and Public Health.2019 6: 1917-1922. DOI: http://dx.doi.org/10.18203/2394-6040.ijcmph20191449

23. Maleki, S., Najafi, F., Farhadi, K., Fakhri, M., Hosseini, F., \& Naderi, M. (2020). Knowledge, Attitude and Behavior of Health Care Workers in the Prevention of COVID-19. 1-17. https://doi.org/10.21203/rs.3.rs-23113/v1.

24. Zhong, B. L., Luo, W., Li, H. M., Zhang, Q. Q., Liu, X. G., Li, W. T., \& Li, Y.Knowledge, attitudes, and practices towards COVID-19 among Chinese residents during the rapid rise period of the COVID-19 outbreak: a quick online cross-sectional survey. International journal of biological sciences.2020. 16(10), 1745-1752. https://doi.org/10.7150/ijbs.45221 
25. Nour, M.O., Babalghith, A.O., Natto, H.A., Alawneh, S.M. and Elamin, F.O. Raising awareness of health care providers about MERSCoV infection in public hospitals in Mecca, Saudi Arabia. East Mediterr Health J.2017;23(8), pp.534.42 https://doi.org/10.26719/2017.23.8.53.

26. Asaad A, El-Sokkary R, Alzamanan M, El-Shafei M. Knowledge and attitudes towards Middle East respiratory sydrome-coronavirus (MERS-CoV) among health care workers in south-western Saudi Arabia. East Mediterr Health J. 2020 Apr 16;26(4):435-442. doi: 10.26719/emhj.19.079. PMID: 32338362.

27. Al-Amri S, Bharti R, Alsaleem SA, Al-Musa HM, Chaudhary S, Al-Shaikh AA. Knowledge and practices of primary health care physicians regarding updated guidelines of MERS-CoV infection in Abha city. J Family Med Prim Care. 2019;8(2):455-461. doi:10.4103/jfmpc.jfmpc336_18.

28. Apisarnthanarak A, Phattanakeitchai P, Warren DK, Fraser VJ. Impact of knowledge and positive attitudes about avian influenza (H5N1 virus infection) on infection control and influenza vaccination practices of Thai healthcare workers. Infect Control Hosp Epidemiol. 2008 May;29(5):472-4. doi: 10.1086/587495. PMID: 18419378.

29. Saqlain, Muhammad, Munir Muhammad, Rehman, Saif , Gulzar, Aqsa, Naz Sahar ,Ahmed, Zaheer, etal .Knowledge, attitude, practice and perceived barriers among healthcare professionals regarding COVID-19: A Cross-sectional survey from Pakistan. Journal of hospital infections 105 (2020) 419423.DOI:10.1101/2020.04.13.20063198.

30. Nas, F., Ali, M., azu, L., Abdallah, M., Yusuf, S. Epidemiology of novel COVID-19 in Nigeria. Microbes and Infectious Diseases, 2020; 1(2): 49-56. doi: 10.21608/mid.2020.103530

31. Bezerra, TB, Valim, MD, Bortolini, J, Ribeiro, RP, Marcon, SR, Moura, MEB. Adherence to hand hygiene in critical sectors: Can we go on like this?. J Clin Nurs. 2020; 29: 2691- 2698.

https://doi.org/10.1111/jocn.15293.

32. Unaib Rabbani and Abdullah Mohammed Al Saigul. Knowledge, Attitude and Practices of Health Care Workers about Corona Virus Disease 2019 in Saudi Arabia. Journal of Epidemiology and Global Health.2020. https://doi.org/10.2991/jegh.k.200819.002

33. Kumar J, Katto MS, Siddiqui AA, Sahito B, Jamil M, Rasheed N, et al. Knowledge, Attitude, and Practices of Healthcare Workers Regarding the Use of Face Mask to Limit the Spread of the New Coronavirus Disease (COVID-19). Cureus. 2020 Apr 20;12(4):e7737. doi: 10.7759/cureus.7737. PMID: 32455057; PMCID: PMC7241223.

34. Thu T, QuocAnh N, QuyChau N and Hung N. Knowledge, Attitude and Practices regarding Standard and Isolation Precautions among Vietnamese Health Care Workers: A Multicenter Cross-Sectional Survey. Internal Medicine:2012. Open Access, 02(04), 2-6. https://doi.org/10.4172/21658048.1000115 .

35. Ogolodom MP, Mbaba AN, Alazigha N, Erondu OF, Egbe NO, Golden I, et al. Knowledge, Attitudes and Fears of HealthCare Workers towards the Corona Virus Disease (COVID-19) Pandemic in SouthSouth, Nigeria. Health Sci J. Sp.2020; Iss 1: 002. DOI: 10.36648/1791-809X.S1.002. 